
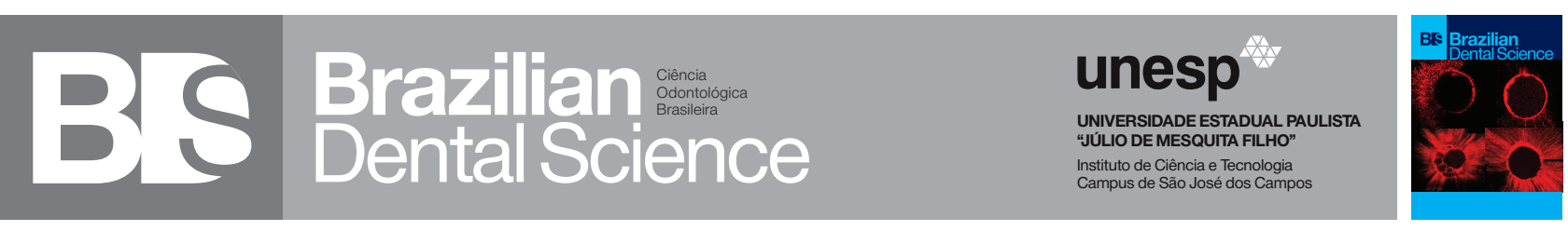

\title{
Comparative Evaluation of ICDAS, WHO and Histological Examination in Detection of Occlusal Carious Lesions
}

Avaliação comparativa de ICDAS, OMS e Exame histológico na detecção de lesões cariosas oclusais

Eman ALAA ${ }^{1}$, Hend El MESSIRY ${ }^{2}$

1 - Department of Pediatric Dentistry and Dental Public Health - Faculty of Oral and Dental Medicine - Future University in Egypt - Cairo - Egypt.

2 - Department of Oral Biology - Faculty of Dentistry - Ain Shams University - Cairo - Egypt.

\begin{abstract}
Detection of occlusal carious lesions with visual scoring systems is in a continuous validation with the histological depth of carious demineralization. Objective: The present study aimed to compare the International Caries Detection and Assessment System (ICDAS), the World Health Organization (WHO) system and histological examination in detecting occlusal carious lesions. Material and Methods: 20 premolars were evaluated by visual examination using ICDAS, WHO and histological examination using stereomicroscope (SM) for occlusal caries detection. Occlusal surfaces were evaluated by two examiners then all teeth were visually and histologically assessed. Results: For each of three systems the inter class correlation coefficient was examined, the differences between the three systems of occlusal caries detection were minimal. The visual examination through WHO recorded the higher intercorrelation coefficient followed by ICDAS system then histological examination respectively. Conclusion: WHO and ICDAS have demonstrated reproducibility and diagnostic accuracy when compared with histological examination for detecting occlusal caries.
\end{abstract}

\section{KEYWORDS}

International caries detection and assessment system; World health organization; Histological examination; Occlusal caries.

\section{RESUMO}

A detecção de lesões cariosas oclusais através de sistemas de pontuação visual está em contínua validação com a profundidade histológica do processo de desminerização da cárie. Objetivo: O presente estudo teve como objetivo comparar o Sistema Internacional de Detecção e Avaliação de Cáries (ICDAS), o Sistema da Organização Mundial da Saúde (OMS) e o exame histológico na detecção de lesões cariosas oclusais. Material e Métodos: 20 pré-molares foram avaliados por exame visual ICDAS, OMS e exame histológico usando estereomicroscópio (SM) para a detecção de cárie oclusal. As superfícies oclusais foram avaliadas por dois examinadores, e todos os dentes foram avaliados visualmente e histologicamente. Resultados: Para cada um dos três sistemas, foi realizada uma análise do coeficiente de correlação interclasses, sendo que a diferença entre os três sistemas de detecção de cárie oclusal foi mínimo. O exame visual através da OMS registrou o maior coeficiente de intercorrelação seguido pelo sistema ICDAS, em seguida, o exame histológico, respectivamente. Conclusão: OMS e ICDAS demonstraram reprodutibilidade e precisão diagnóstica quando comparado com o exame histológico para detecção de cáries oclusais

\section{PALAVRAS-CHAVE}

Sistema de detecção e avaliação internacional de cáries; Organização mundial de saúde; Exame histológico; Cárie oclusal. 


\section{INTRODUCTION}

$\mathrm{D}$ ental caries continues to be the major challenge that attracts the attention of public health and clinical dentists. This is encountered in dental practice, research dental education and dental epidemiology thus the most popular means of caries determination and detection is enforced. Recently this conducted the expansion of literature about how to diagnose and determine carious lesions in different settings. [1]

Visual inspection of tooth surfaces is the standard and traditional technique used. Many improvements have been considered in the development of novel technologies that help in carious lesions detection. This aids for detection of caries to expand the sensitivity of visual detection of caries and preserving a high degree of specificity [2]. Most of these systems and techniques were validated by using methods for visual caries detection [3-5]. The great need for reliable methods for caries detection has however led to the development of visual systems as ICDAS and WHO systems.

Although occlusal surfaces records represents only $12.5 \%$ of surfaces exposed to caries attack; studies in literature have shown that between $80-90 \%$ of the overall carious lesions that have happened during childhood and adolescence stages are located in occlusal pits and surfaces [6,7]. Given that these carious lesions have an increased incidence and they require quiet a long time to turn into cavitary lesions [8]. Dentists may find these lesions in various stages of their evolution and manage them as conservatively as possible.

A lot of the earlier research that was based on the correlation between clinical and histologic changes of the carious lesions, revealed an elevated specificity of the visual diagnosis [9]. However; the low sensitivity of the visual method in the detection of the initial signs of the carious lesions makes dentists underestimate the prevalence of the carious lesions; so, many of the carious lesions remain either untreated [10] or over treated by sealing.

In most of the epidemiological surveys; the carious lesions are diagnosed using the WHO criteria. There are three of the four criteria of this system that could help make a diagnosis for irreversible stages of the carious lesions; characterized by enamel disruption or dentin exposure. Most probably, these carious lesions are much extended into dentin and are evolving very rapidly [11]. Hence, it is necessary to introduce more subtle diagnostic systems; that can record carious lesions in their noncavitary early stages. The ICDAS system allows clinicians, researchers and epidemiologists to make a better diagnosis based on the objective clinical signs; standardizing all the collected data and then comparing them to similar studies. This system not only provides a great understanding of the carious lesions, but also helps in its management within each individual as well as among the whole population [12]. Systematizing the literature regarding the systems of clinical carious lesions detection [9] and also data from other sources [13-18] greatly helped building up international consensus on diagnosing many occlusal carious diseases.

The current study was conducted to compare the validity of ICDAS system, WHO system and the histological examination in the detection of incipient occlusal carious lesions.

\section{MATERIAL AND METHODS}

\section{Samples selection}

Sample consisted of 20 extracted human premolars from output clinics of oral and maxillofacial surgery of Ain Shams University 
and Future University in Egypt. Teeth with crown fracture, restorations, calculus remnants and endodontic treatments were excluded from the study. Teeth were cleaned then washed with distilled water and were kept in $0.02 \%$ sodium azyde solution.

\section{Examination methods}

Premolars were then evaluated by visual examination using ICDAS and WHO criteria and histologically using stereomicroscope (SM) for detection of carious lesions. The surfaces were visually evaluated by two examiners who have been trained in utilizing both systems of carious lesions detection. Each examiner analyzed every premolar independently after being dried by water/air spray of the unit. All the premolars were examined wet and also after being dried with compressed air.

Visual examination with Caries Detection and Assessment System (ICDAS) criteria

Occlusal surfaces of teeth were positioned at an average of $25 \mathrm{~cm}$ from the eyes of each examiner, in a highly illuminated room, and then examined in both wet and dry conditions; (drying is done with compressed air for about 5 seconds independently by each examiner). The examiners applied independently the ICDAS scoring [19]; in which score 0 represents a sound tooth surface, score 1 ; represents enamel opacity or discoloration which is visible after air drying of the surface, score 2; represents enamel opacity discoloration; which is visible when the surface is wet and also still visible after air drying, score 3; represents localized breakdown in opaque or discolored enamel before and after air drying, score 4; represents an underlying dark shadow within dentin with/without enamel breakdown, score 5; represents distinct dentin cavitation and score
6; represents distinct dentin cavitation that involves more than half of the occlusal surface.

Visual examination with the World Health Organization (WHO) criteria

Occlusal surfaces of teeth were positioned at an average of $25 \mathrm{~cm}$ from the eyes of each examiner, in a highly illuminated room, and then examined in both wet and dry conditions; (drying is done with compressed air for about 5 seconds independently by each examiner)., the examiners applied independently the WHO scoring [20]; D0 represents sound surface of the tooth, D1 represents non cavitary enamel lesion, D2 represents cavitary lesion in enamel, D3 represents cavitary lesion in dentin and D4 represents cavitary lesion in dentin with pulp complications.

\section{Histological examination using stereomicroscopy (SM)}

Undemineralized longitudinal sections for each premolar were prepared and were oriented buccolingually, sectioned with a diamond disc of $0.15 \mathrm{~mm}$ thick using a low speed motor with water irrigation. Each section was given a score for the lesion depth according to the following histological scoring system; 0 represents no enamel demineralization or edge phenomenon, 1 represents demineralization which is limited to the outer $50 \%$ of enamel, 2 represents demineralization between the inner $50 \%$ of enamel and the outer third of dentin, 3 represents demineralization which involves the middle third of dentin and 4 represents demineralization that involves the inner third of dentin. Then each section was scored histologically according to the lesion depth by using the SM with no contrast solution. These sections were then classified according to Ekstrand criteria [21] as shown in table I. 
Table I - The categorical frequency distribution of studied teeth based on the level of dye penetration in the test groups in millimeters.

\begin{tabular}{|c|c|c|c|c|}
\hline & ICDAS criteria & & WHO criteria & Histological examination \\
\hline Code 0 & $\begin{array}{l}\text { Sound tooth surface with no evidence of caries after } \\
\text { air drying for five seconds }\end{array}$ & D0 & $\begin{array}{l}\text { Sound tooth } \\
\text { surface }\end{array}$ & No enamel demineralization or edge phenomenon \\
\hline Code1 & $\begin{array}{l}\text { First visual changes in enamel (opacity or discolo- } \\
\text { ration); which is visible at the entrance to the pits or } \\
\text { fissures after air drying (not or hardly seen on a wet } \\
\text { surface) }\end{array}$ & D1 & $\begin{array}{l}\text { Non cavitary } \\
\text { enamel lesion }\end{array}$ & $\begin{array}{l}\text { Enamel demineralization which is limited to outer } 50 \% \\
\text { of enamel }\end{array}$ \\
\hline Code 2 & $\begin{array}{l}\text { Distinct visual changes in enamel (opacity/ discolo- } \\
\text { ration); which is visible at the entrance to the pit and } \\
\text { fissure when wet (lesion must still be visible when } \\
\text { dry) }\end{array}$ & & & $\begin{array}{l}\text { Demineralization that involves } \\
\text { inner } 50 \% \text { of enamel and outer third of dentin }\end{array}$ \\
\hline Code 3 & $\begin{array}{l}\text { Localized enamel break down as a result of } \\
\text { caries, with no visible dentin or any underlying sha- } \\
\text { dow (opacity/discoloration) wider than the natural } \\
\text { fissure/fossa when wet and after prolonged drying }\end{array}$ & D2 & $\begin{array}{l}\text { Cavitary } \\
\text { enamel lesion }\end{array}$ & \\
\hline Code 4 & $\begin{array}{l}\text { Underlying dark shadow from dentin and localized } \\
\text { breakdown of enamel }\end{array}$ & D3 & $\begin{array}{c}\text { Cavitary } \\
\text { dentinal lesion }\end{array}$ & Demineralization that involves middle third of dentin \\
\hline Code 5 & $\begin{array}{l}\text { Distinct cavitation with visible dentin (visual evidence } \\
\text { of demineralization and exposed dentin) }\end{array}$ & & & \\
\hline Code 6 & $\begin{array}{l}\text { Extensive distinct cavitation with visible dentin and } \\
\text { more than half of the surface were involved }\end{array}$ & & $\begin{array}{l}\text { Cavitary lesion with pulp com- } \\
\text { plication }\end{array}$ & H4 Demineralization which involves the inner third of dentin \\
\hline
\end{tabular}

\section{RESULTS}

Out of the twenty lesions which were included in the present study using the ICDAS examination, WHO system and histological examination; the 2 (10\%) carious lesions which were included in the 0 category by using the ICDAS examination, were confirmed by the WHO system to be D0 and also 2 were confirmed by histological examination to be HO.

As for the 5 (25\%) carious lesions which received score 1 at ICDAS examination the 5 were confirmed by WHO system to be D1, 3 carious lesions we certified to be H1, 1 lesion in higher score category $\mathrm{H} 2$ and 1 lesion in lower score category HO.

Regarding the 4 (20\%) carious lesions scored 2 in ICDAS; 1 were confirmed as D2 in WHO system and 3 with a lower score category D1, 3 were confirmed as $\mathrm{H} 1$ in histological examination and 1 with a lower score category H0. As for the $7(35 \%)$ carious lesions with score 3 in ICDAS; the 7 were confirmed to be D2 in WHO system while 2 were confirmed to be H2 histological examination, 2 with lower score category and 3 with high score category. Regarding the $2(10 \%)$ carious lesions with score 4 in ICDAS system, 2 were confirmed to be D3 with WHO system and 1 confirmed with $\mathrm{H} 3$ in histological examination and 1 with lower score category $\mathrm{H} 2$ as shown in table II and figure 1.

Table II - ICDAS, WHO and histological examination criteria

\begin{tabular}{|c|c|c|c|}
\hline \multirow{2}{*}{\multicolumn{2}{|c|}{ Variables }} & \multicolumn{2}{|c|}{ Carious Lesions Examinations } \\
\hline & & n & $\%$ \\
\hline \multirow{7}{*}{ ICDAS } & 0 & 2 & $10 \%$ \\
\hline & 1 & 5 & $25 \%$ \\
\hline & 2 & 4 & $20 \%$ \\
\hline & 3 & 7 & $35 \%$ \\
\hline & 4 & 2 & $10 \%$ \\
\hline & 5 & - & - \\
\hline & 6 & - & - \\
\hline \multirow{5}{*}{ WHO } & D0 & 2 & $10 \%$ \\
\hline & D1 & 8 & $40 \%$ \\
\hline & D2 & 8 & $40 \%$ \\
\hline & D3 & 2 & $10 \%$ \\
\hline & D4 & - & - \\
\hline \multirow{5}{*}{ Histological } & HO & 4 & $20 \%$ \\
\hline & $\mathrm{H} 1$ & 8 & $40 \%$ \\
\hline & $\mathrm{H} 2$ & 4 & $20 \%$ \\
\hline & H3 & 4 & $20 \%$ \\
\hline & $\mathrm{H} 4$ & - & - \\
\hline
\end{tabular}




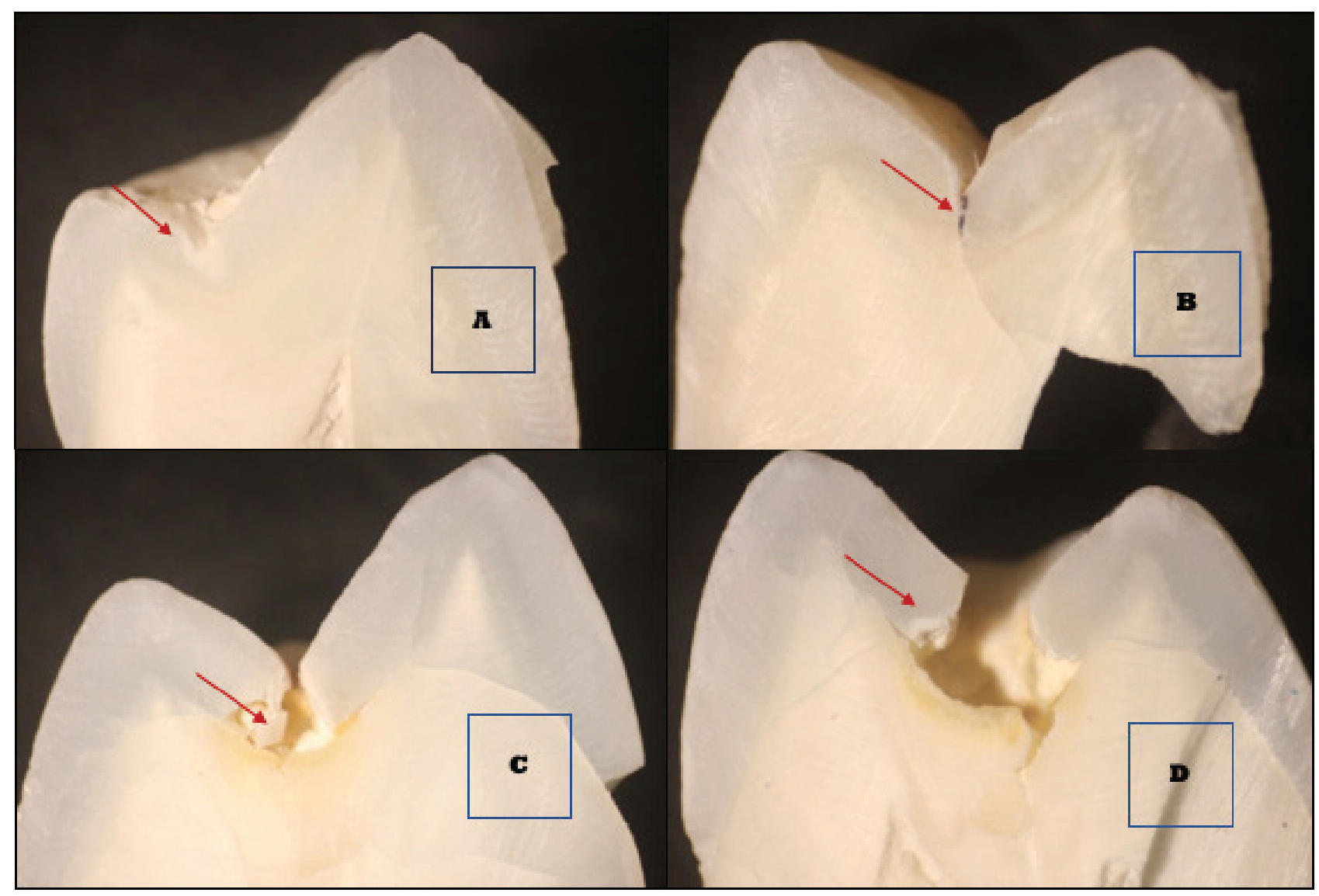

Figure 1 - Photograph of SM showing: a) HO score with edge phenomenon (arrow), b) H1 score with enamel demineralization only limited to outer 50\% of enamel (arrow), c) H2 score with a demineralized lesion involving 50\% of enamel and outer third of dentin (arrow) and d) $\mathrm{H} 3$ score with a demineralized lesion involving enamel and middle third of dentin (arrow).

For each of three systems the inter class correlation coefficient was examined, A statistically significance difference was found between ICDAS and WHO examinations where $(\mathrm{p}<0.001)$ with inter class correlation coefficient (ICC) (0.946) which states a very strong reliability and agreement between the two examinations. Also statistically significance difference was found between ICDAS and Histological examinations where $(p<0.001)$ with inter class correlation coefficient (ICC) (0.727) which states a strong reliability and agreement between the two examinations and a statistically significance difference was found between WHO and histological examinations where $(p<0.001)$ with inter class correlation coefficient (ICC) (0.748) which states a strong reliability and agreement between the two systems. Differences between the three examination systems in detection of occlusal caries were very minimal. The WHO visual examination recorded highest inter correlation coefficient followed by ICDAS system then histological examination respectively as shown in table III. 
Table III - ICDAS, WHO and histological examination correlation coefficient.

\begin{tabular}{|c|c|c|c|c|c|}
\hline \multicolumn{6}{|c|}{ Correlations } \\
\hline & & & WHO criteria & WHO criteria & WHO criteria \\
\hline \multirow{9}{*}{ Spearman } & \multirow{3}{*}{ ICDAS } & $\begin{array}{l}\text { Correlation } \\
\text { Coefficient }\end{array}$ & 1.000 & $.946^{\star \star}$ & $.727^{\star \star}$ \\
\hline & & Sig. (2-tailed) & & .000 & .000 \\
\hline & & $\mathbf{N}$ & 20 & 20 & 20 \\
\hline & \multirow{3}{*}{ Spearman } & $\begin{array}{l}\text { Correlation } \\
\text { Coefficient }\end{array}$ & $.946^{\star \star}$ & 1.000 & $.748^{\star \star}$ \\
\hline & & Sig. (2-tailed) & .000 & & .000 \\
\hline & & $\mathbf{N}$ & 20 & 20 & 20 \\
\hline & \multirow{3}{*}{ Spearman } & $\begin{array}{l}\text { Correlation } \\
\text { Coefficient }\end{array}$ & $.727^{\star \star}$ & $.748^{\star \star}$ & 1.000 \\
\hline & & Sig.(2-tailed) & .000 & .000 & \\
\hline & & $\mathbf{N}$ & 20 & 20 & 20 \\
\hline
\end{tabular}

Relationship and Inter-observers reliability between two readings for different groups as shown in table IV.

1) ICDAS:

A statistically significance difference was found between the two readings where $(\mathrm{p}<0.001)$ with inter class correlation coefficient (ICC) (0.974) which states a strong reliability and agreement between the two readings.

2) WHO:

A statistically significance difference was found between the two readings where $(\mathrm{p}<0.001)$ with inter class correlation coefficient (ICC) (0.946) which states a strong reliability and agreement between the two readings.

\section{3) Histological:}

A statistically significance difference was found between the two readings where $(\mathrm{p}<0.001)$ with inter class correlation coefficient (ICC) (0.954) which states a strong reliability and agreement between the two readings.
Table IV - Table showing relationship between the two readings for different groups.

\begin{tabular}{ccccccc|}
\hline Measurements & Groups & Mean & S.D. & p-value & ICC \\
\hline \multirow{2}{*}{ ICDAS } & First Examiner & 2.10 & 1.21 & $<0.01^{*}$ & 0.974 \\
& Second Examiner & 2.00 & 0.98 & & \\
\multirow{2}{*}{ WHO } & First Examiner & 1.50 & 0.83 & $<0.001^{*}$ & 0.946 \\
& Second Examiner & 1.32 & 0.74 & & \\
Histological & First Examiner & 1.40 & 1.05 & $<0.001^{*}$ & 0.954 \\
& Second Examiner & 1.29 & 0.98 & & \\
*; signifiant $(p \leq 0.05) \quad n s ;$; non-signifiant $(p>0.05)$. &
\end{tabular}

\section{DISCUSSION}

Occlusal carious lesions diagnosis is not considered to be a simple yes or no decision; as several aspects have to be considered. Recognizing surface color changes, intrinsic and also extrinsic reasons have to be assessed. The opacities which are related to enamel developmental defects must be differentiated from demineralization and carious lesions. Therefore; the rough enamel structures denotes active decay. Also, dry tooth surface can be checked for chalkiness. If there is a doubt concerning a real cavitation of the surface; a ball ended probe shall be used for the gentle inspection of surface texture and this is done to detect if there is any discontinuity or breakdown. The reason for the differentiated carious lesions diagnosis is that non cavitated carious lesions can remineralize without tooth 
damage and that occurs if the crystalline structure has not been damaged. [22]

In histology, a carious lesion is represented by the carious infected dentin which include demineralized infected dentin and carious affected dentin which includes demineralized but neither infected nor sclerotic [23]. The depth of carious lesion of dentin is the sum of depths of demineralized dentin zones in caries infected and affected zones. The depth of the lesion does not include sclerotic dentin [21,24].

The present study aimed to validate visual scoring systems and histological assessment by comparing ICDAS and WHO visual results to histologically observable carious lesions. Thus; it is found that both visual techniques show more or less strong correlation to the histologically apparent carious lesions.

Results of the current study showed that the differences between the three techniques of occlusal carious lesions detection were very minimal. Assessing the feasibility of utilizing the ICDAS system in epidemiological surveys and comparing ICDAS system with WHO criteria in previous studies have shown that ICDAS was very comparable to the standard criteria when the cut off value was score 3 [25]. Similar study revealed that the least differences between ICDAS II and WHO systems at cut off point 3 [26].

It could be revealed that ICDAS showed the best results in clean and also in dry teeth as well as when the examiners were well trained [27-29]. In the current study; all the teeth were cleaned, kept moist during the whole period of examination and earliest visual signs of carious lesions was revealed using compressed air. A strict regimen was followed to avoid any personal bias; examination, assessment and scoring of all the teeth were performed by the two examiners of the study independently.
A recent study assessed ICDAS scoring versus radiographic evaluation of occlusal surfaces as well as their association with treatment and management decisions. [30]. The results of this assessment are in accordance with those of the current study as data suggested that the visual evaluation by ICDAS scoring system showed better performance for the detection of occlusal caries lesions.

Histological assessment of caries was used as a gold standard in the current study. Different magnification and staining techniques were also used in previous studies to histologically evaluate the carious lesion extent. However, other previous studies have done their research without the staining technique and evaluated the carious tissues at a magnification of 16-fold. [24]

\section{CONCLUSION}

WHO and ICDAS systems have demonstrated high reproducibility and diagnostic accuracy when compared with histological examination for detecting occlusal carious lesions thus they are considered an adjunct method to clinical decision making and preventive treatment planning.

\section{Declaration of funding and conflicts of interest}

This research did not receive any specific grant from funding agencies in the public, commercial or not for profit sectors and has no conflicts of interest.

\section{REFERENCES}

1. Baelum V. What is an appropriate caries diagnosis? Acta Odontol Scand. 2010;68(2):65-79. doi:10.3109/00016350903530786.

2. Neuhaus KW, Ellwood R, Lussi A, Pitts NB. Traditional lesion detection aids. Monogr Oral Sci. 2009;21:42-51. doi:10.1159/000224211.

3. Karlsson L, Johansson E, Tranaeus S. Validity and reliability of laserinduced fluorescence measurements on carious root surfaces in vitro. Caries Res. 2009;43(5):397-404. doi:10.1159/000239754.

4. Kühnisch J, Ifland S, Tranaeus S, Heinrich-Weltzien R. Comparison of visual inspection and different radiographic methods for dentin caries 
detection on occlusal surfaces. Dentomaxillofac Radiol. 2009;38(7):452-7. doi:10.1259/dmfr/34393803.

5. Sridhar N, Tandon S, Rao N. A comparative evaluation of DIAGNOdent with visual and radiography for detection of occlusal caries: an in vitro study. Indian J Dent Res. 2009;20(3):326-31. doi:10.4103/0970-9290.57376.

6. Ripa LW, Leske GS, Varma AO. Longitudinal study of the caries susceptibility of occlusal and proximal surfaces of first permanent molars. J Public Health Dent. 1988;48(1):8-13. doi:10.1111//1752-7325.1988.tb03154.x

7. Anderson M. Risk assessment and epidemiology of dental caries: review of the literature. Pediatr Dent. 2002;24(5):377-85.

8. Vehkalahti MM, Widström E. Teaching received in caries prevention and perceived need for Best Practice Guidelines among recent graduates in Finland. Eur J Dent Educ. 2004;8(1):7-11. doi:10.1111/.j16000579.2004.00327.x.

9. Ismail Al. Visual and visuo-tactile detection of dental caries. J Dent Res. 2004;83 Spec No C:C56-C66. doi:10.1177/154405910408301s12.

10. Lussi A, Imwinkelried S, Pitts N, Longbottom C, Reich E. Performance and reproducibility of a laser fluorescence system for detection of occlusal caries in vitro. Caries Res. 1999;33(4):261-6. doi:10.1159/000016527.

11. WHO. Oral Health Surveys: Basic Methods, Ed 4. Geneva, World Health Organization. 1997.

12. Pitts N. "ICDAS"--an international system for caries detection and assessment being developed to facilitate caries epidemiology, research and appropriate clinical management. Community Dent Health. 2004;21(3):193-8.

13. Ekstrand KR, Ricketts DN, Kidd EA. Reproducibility and accuracy of three methods for assessment of demineralization depth of the occlusal surface: an in vitro examination. Caries Res. 1997;31(3):224-31. doi:10.1159/000262404.

14. Fyffe HE, Deery C, Nugent ZJ, Nuttall NM, Pitts NB. Effect of diagnostic threshold on the validity and reliability of epidemiological caries diagnosis using the Dundee Selectable Threshold Method for caries diagnosis (DSTM). Community Dent Oral Epidemiol. 2000;28(1):42-51. doi:10.1034/ j.1600-0528.2000.280106.x

15. Ekstrand KR, Ricketts DN, Kidd EA. Occlusal caries: pathology, diagnosis and logical management. Dent Update. 2001;28(8):380-7. doi:10.12968/ denu.2001.28.8.380

16. Chesters RK, Pitts NB, Matuliene G, Kvedariene A, Huntington E, Bendinskaite R, et al. An abbreviated caries clinical trial design validated over 24 months. J Dent Res. 2002;81(9):637-40. doi:10.1177/15440591020 8100912.

17. Ricketts DN, Ekstrand KR, Kidd EA, Larsen T. Relating visual and radiographic ranked scoring systems for occlusal caries detection to histological and microbiological evidence. Oper Dent. 2002;27(3):231-7.
18. Ekstrand KR, Ricketts DN, Longbottom C, Pitts NB. Visual and tactile assessment of arrested initial enamel carious lesions: an in vivo pilot study. Caries Res. 2005;39(3):173-7. doi:10.1159/000084794.

19. Ismail Al, Sohn W, Tellez M, Amaya A, Sen A, Hasson H, et al. The International Caries Detection and Assessment System (ICDAS): an integrated system for measuring dental caries. Community Dent Oral Epidemiol. 2007;35(3):170-8. doi:10.1111/j.1600-0528.2007.00347.x.

20. Stoleriu S, Pancu G, lovan G, Ghiorghe A, Andrian S. Comparative Study Regarding Who And Icdas-II System Of Detection Of Occlusal Caries. J Rom Oral Rehab. 2012;4(2):5-10.

21. Ekstrand KR, Kuzmina I, Bjørndal L, Thylstrup A. Relationship between external and histologic features of progressive stages of caries in the occlusal fossa. Caries Res. 1995;29(4):243-50. doi:10.1159/000262076.

22. Featherstone JD. Dental caries: a dynamic disease process. Aust Dent J. 2008;53(3):286-91. doi:10.1111/j.1834-7819.2008.00064.x.

23. Ogawa K, Yamashita Y, Ichijo T, Fusayama T. The ultrastructure and hardness of the transparent layer of human carious dentin. J Dent Res. 1983;62(1):7-10. do::10.1177/00220345830620011701.

24. Jablonski-Momeni A, Stachniss V, Ricketts DN, Heinzel-Gutenbrunner M, Pieper K. Reproducibility and accuracy of the ICDAS-II for detection of occlusal caries in vitro. Caries Res. 2008;42(2):79-87. doi:10.1159/000113160.

25. Braga MM, Oliveira LB, Bonini GA, Bönecker M, Mendes FM. Feasibility of the International Caries Detection and Assessment System (ICDAS-II) in epidemiological surveys and comparability with standard World Health Organization criteria. Caries Res. 2009;43(4):245-9. doi:10.1159/000217855.

26. Iranzo-Cortés JE, Montiel-Company JM, Almerich-Silla JM. Caries diagnosis: agreement between WHO and ICDAS II criteria in epidemiological surveys. Community Dent Health. 2013;30(2):108-11.

27. Ekstrand KR, Martignon S, Ricketts DJ, Qvist V. Detection and activity assessment of primary coronal caries lesions: a methodologic study. Oper Dent. 2007;32(3):225-35. doi:10.2341/06-63.

28. Gomez J, Zakian C, Salsone S, Pinto SC, Taylor A, Pretty IA, et al. In vitro performance of different methods in detecting occlusal caries lesions. J Dent. 2013;41(2):180-6. doi:10.1016/j.jdent.2012.11.003.

29. El-Damanhoury HM, Fakhruddin KS, Awad MA. Effectiveness of teaching International Caries Detection and Assessment System II and its e-learning program to freshman dental students on occlusal caries detection. Eur J Dent. 2014;8(4):493-7. doi:10.4103/1305-7456.143631.

30. Diniz MB, Lima LM, Eckert G, Zandona AG, Cordeiro RC, Pinto LS. In vitro evaluation of ICDAS and radiographic examination of occlusal surfaces and their association with treatment decisions. Oper Dent. 2011;36(2):13342. doi:10.2341/10-006-L.

\section{Eman Alaa}

\section{(Corresponding address)}

Department of Pediatric Dentistry and Dental Public Health, Faculty of Oral and Den-

tal Medicine, Future University in Egypt, Cairo, Egypt.

Address: Sherook City, Street Abdel Monem Wasl, Villa 37, Cairo, Egypt

Date submitted: 2019 Nov 07

E-mail: eman_afm@yahoo.com 